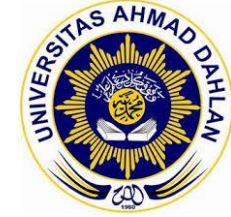

BERKALA FISIKA INDONESIA

Jurnal IImiah Fisika, Pembelajaran dan Aplikasinya

http://journal.uad.ac.id/index.php/BFI/index 2085-0409 (Print) | 2550-0465 (online)

\title{
Penentuan koefisien pemuaian panjang logam menggunakan metode difraksi celah tunggal
}

\author{
Hikmatun Isnawati ${ }^{1 *}$, Siti Anisatur Rofiqah ${ }^{2}$, M. Firman Ramadhan ${ }^{3}$ \\ 1 Pendidikan Fisika, Fakultas Keguruan dan Ilmu Pendidikan, Universitas Ahmad Dahlan, Indonesia \\ 2 Pendidikan Fisika, Sekolah Tinggi Keguruan dan Ilmu Pendidikan Nurul Huda, Indonesia \\ ${ }^{3}$ Pendidikan Fisika, Fakultas Keguruan dan Ilmu Pendidikan, Universitas Muhammadiyah Mataram, Indonesia \\ Email: isna13.iw@gmail.com* \\ * Penulis korespondensi
}

\begin{tabular}{l}
\hline Informasi artikel \\
\hline Sejarah artikel: \\
Dikirim \\
Revisi \\
Diterima
\end{tabular}

\section{Kata kunci:}

Difraksi celah tunggal

Koefisien pemuaian logam

Regresi linier

\begin{abstract}
ABSTRAK
Abstrak tidak memuat sitasi, rumus, tabel dan gambar. Abstrak menjelaskan intisari dari Penelitian ini bertujuan untuk menentukan koefisien pemuaian panjang logam Alumunium (Al), Seng ( $\mathrm{Zn})$ dan Tembaga (Cu). Metode yang digunakan adalah difraksi celah tunggal. Penentuan koefisien pemuaian menggunakan pendekatan regresi linear antara perubahan suhu $(T)$ terhadap seperlebar difraksi (1/Z). Pengukuran lebar difraksi dilakukan pada setiap kenaikan suhu $5^{\circ} \mathrm{C}$ dengan mengunakan penggaris dengan tingkat ketelitian hingga orde milimeter. Berdasarkan analisis yang dilakukan koefisien muai Alumunium, Seng dan Tembaga masing-masing sebesar $(29,597549 \pm 0,000045) \times 10^{-6}\left({ }^{\circ} \mathrm{C}\right)^{-1},(32,065406 \pm$ $0,000096) \times 10^{-6}\left({ }^{\circ} \mathrm{C}\right)^{-1}$, dan $(11,622974 \pm 0,000013) \times 10^{-6}\left({ }^{\circ} \mathrm{C}\right)^{-1}$.
\end{abstract}

This is an open access article under the CC-BY-SA license

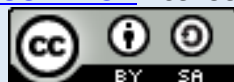

\section{Keywords:}

Single slit diffraction Metal expansion coefficient Linear regression

\begin{abstract}
Determination of the metal length expansion coefficient using the single slit diffraction method. This study aims to determine the length expansion coefficient of aluminium (Al), zinc $(\mathrm{Zn})$ and copper $(\mathrm{Cu})$ metals. The method used is single slit diffraction. The determination of the expansion coefficient uses a linear regression approach between the change in temperature $(T)$ and the diffraction width (1/Z). Measurement of diffraction width is carried out every $5^{\circ} \mathrm{C}$ temperature increase using a ruler with an accuracy level of up to the order of millimetres. Based on the analysis carried out, aluminium's expansion coefficient, zinc and copper is (29.597549 \pm 0.000045$) \times 10^{-6}\left({ }^{\circ} \mathrm{C}\right)^{-1},(32.065406 \pm 0.000096)$ $\times 10^{-6}\left({ }^{\circ} \mathrm{C}\right)^{-1}$, and $(11.622974 \pm 0.000013) \times 10^{-6}\left({ }^{\circ} \mathrm{C}\right)^{-1}$, respectively.
\end{abstract}

\section{How to Cite:}

Isnawati, H., Rofiqah, S. A., \& Ramadhan, M. F. (2020). Penentuan koefisien pemuaian panjang logam menggunakan metode difraksi celah tunggal. Berkala Fisika Indonesia: Jurnal Ilmiah Fisika, Pembelajaran dan Aplikasinya, 11(1), 10-17. 


\section{Pendahuluan}

Pada umumnya, benda akan memuai jika dipanaskan, seperti logam. Logam mempunyai jenis pemuaian yang berbeda-beda (Abdullah, 2016). Koefisien muai adalah metrik yang menentukan tingkat muai. Koefisien muai menentukan bagaimana ukuran benda bertambah seiring perubahan suhu (Usman \& Rahmawati, 2016). Koefisien muai padatan dan zat cair biasanya tidak dipengaruhi oleh tekanan, meskipun dapat berubah seiring dengan suhu (Yantidewi et al., 2018). Akibatnya, koefisien muai panjang mengacu pada potensi pertambahan panjang, luas, dan volume akibat perubahan suhu (Jua et al., 2017). Semakin tinggi koefisien muai panjang logam, semakin besar logam tersebut dapat memuai (Sugianto, 2007).

Para peneliti menggunakan metode difraksi cahaya yang mengalir melalui celah sempit tunggal untuk menghitung perbedaan fraksional dalam ukuran per derajat, perubahan suhu pada regangan konstan, dan perubahan suhu pada tekanan konstan. Difraksi adalah pelenturan gelombang yang disebabkan oleh perambatannya melalui celah yang agak sempit (Serway \& Jewwet, 2010). Percobaan ini bertujuan untuk menentukan koefisien pemuaian panjang logam dengan menggunakan variasi jenis logam yaitu Alumunium (Al), Seng ( $\mathrm{Zn}$ ) dan Tembaga (Cu). Pendekatan yang digunakan dalam penelitian ini adalah dengan membuat celah kecil pada logam, kemudian memanaskannya melalui media air. Penelitian lain menentukan koefisien pemuaian juga bisa dilakukan dengan metode kapasitansi (Yogaswara \& Latief, 2018), teknik Transformer variable (Evans \& Morgan, 1991), Interferometer laser Fabry-Perot (Bharmanee et al., 2008) dan Interferometer laser Michelson (Wolff \& Eselun, 1979). Metode absolut dan relatif adalah dua metode untuk menentukan koefisien muai akibat perubahan suhu. Metode absolut melibatkan penyesuaian dimensi sampel secara linier sehingga setiap perbedaan suhu dapat ditentukan secara langsung. Sedangkan metode relatif dilakukan dengan membandingkan rasionya terhadap konstanta koefisien termal dan bahan acuan yang diketahui (Ferawati \& Okimustava, 2012).

Hasan Fakhruddin menggunakan pendekatan difraksi celah tunggal untuk menghitung koefisien muai Aluminium (Al) dengan memperhatikan pengaruh kenaikan suhu terhadap lebar difraksi. Koefisien muai panjang aluminium percobaan adalah $24,0 \times 10^{-6} /{ }^{\circ} \mathrm{C}$, lebih tinggi dari nilai referensi $23,1 \times 10^{-6}$ $1{ }^{\circ} \mathrm{C}$ dengan kesalahan 3,90\% (Fakhruddin, 2006). Bharmanee melakukan penelitian lain dengan menggunakan pendekatan pola difraksi dalam menutup celah untuk mengetahui nilai koefisien muai panjang aluminium (Bharmanee et al., 2008). Koefisien muai panjang aluminium eksperimental adalah $22,512 \times 10^{-6}{ }^{\circ} \mathrm{C}$, yang terlalu kecil dibandingkan dengan nilai referensi, sehingga menghasilkan kesalahan 2,545\%. Sedangkan peneliti akan melakukan penelitian menggunakan jenis logam yang tidak hanya Alumunium (Al) saja melainkan menggunakan jenis logam berupa Seng (Zn). Pendekatan regresi linier terhadap hubungan antara variasi suhu dan lebar difraksi digunakan untuk menentukan nilai koefisien muai panjang untuk berbagai bentuk logam. Perhitungan menggunakan analisis regresi linier 
digunakan agar perolehan nilai koefisien muai panjang jenis logam menjadi lebih teliti (Pujayanto et al., 2016).

\section{Metode}

Metode penelitian yang digunakan dalam penelitian ini adalah metode difraksi cahaya pada celah tunggal (Sariyanto et al., 2014). Aluminium (Al), Tembaga (Cu), dan Seng ( $\mathrm{nn}$ ) adalah sampel yang digunakan. Gambar 1 menggambarkan konfigurasi peralatan.

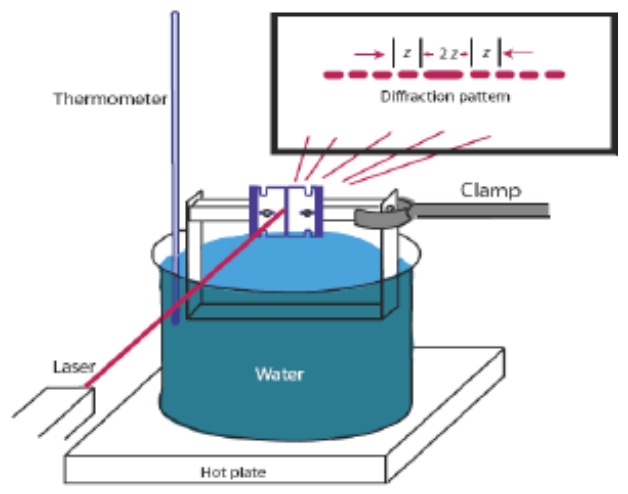

Gambar 1. Apparatus (Wulandari \& Radiyono, 2015)

Berdasarkan rancangan apparatus di atas, maka alat yang yang digunakan untuk pengambilan data dapat dilihat pada Gambar 2. Pola difraksi, pola gelap, dan pola cahaya dibuat saat sinar laser ditembakkan melalui celah sempit. Ketika setup alat telah dilakukan, penentuan koefisien pemuaian dilakukan dengan mengukur durasi pola difraksi setiap kali sinar laser ditembakkan pada kenaikan suhu tertentu. Percobaan ini direplikasi pada temperatur yang berbeda, dengan kenaikan 5 derajat Celcius. Analisis regresi linier $T$ terhadap $1 / Z$ menggunakan program Microsoft Excel, yang menghasilkan $a$ dan b. Persamaan (3) digunakan untuk menentukan nilai $a$, dan persamaan (4) digunakan untuk mengukur ralatnya.

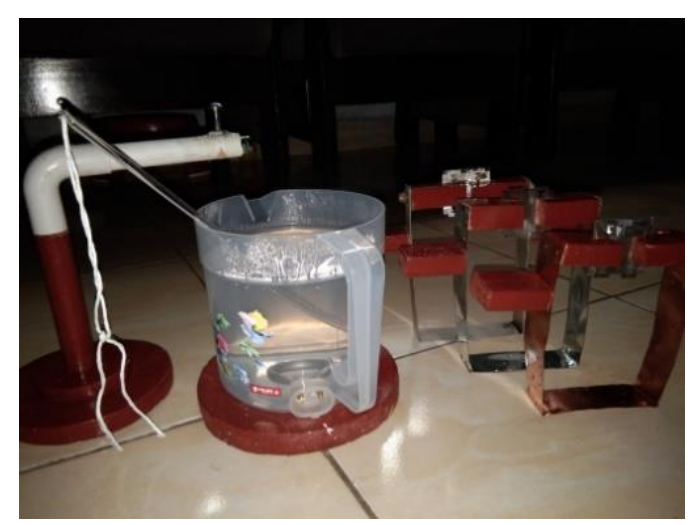

Gambar 2. Alat percobaan

$$
\frac{1}{Z}=\frac{\alpha L_{0}}{\lambda D} T+\left(\frac{1}{Z_{0}}-\frac{\alpha L_{0} T_{0}}{\lambda D}\right)
$$


Persamaan (1) dapat diselesaikan dengan menggunakan pendekatan persamaan linier

$$
y=a x+b
$$

dengan $a=\frac{\alpha L_{0}}{\lambda D}$ kemiringan garis dan $b=\left(\frac{1}{z_{0}}-\frac{\alpha L_{0} T_{0}}{\lambda D}\right)$ merupakan intersep pada sumbu y. Dari nilai $a$, maka diperoleh persamaan (3)

$$
\alpha=\frac{a \lambda D}{L_{0}}
$$

Ralat $\alpha$ dapat ditentukan melalui teori perambatan ralat pada persamaan (4)

$$
S_{\alpha}=\left\{\left(\frac{\partial \alpha}{\partial a} S_{a}\right)^{2}+\left(\frac{\partial \alpha}{\partial \lambda} S_{\lambda}\right)^{2}+\left(\frac{\partial \alpha}{\partial D} S_{D}\right)^{2}+\left(\frac{\partial \alpha}{\partial L_{0}} S_{L_{0}}\right)^{2}\right\}
$$

\section{Hasil dan Pembahasan}

Data lebar kisi difraksi pada setiap kenaikan suhu $5^{\circ} \mathrm{C}$ seperti yang ditunjukkan pada Tabel 1. Nilai lebar difraksi yang dihasilkan semakin berkurang seiring dengan kenaikan suhu. Logam aluminium (Al) memuai seiring kenaikan suhu air panas, menghasilkan lebar difraksi yang lebih sempit. Dari data yang diperoleh, maka grafik yang terbentuk antara perubahan suhu setiap kenaikan $5^{\circ} \mathrm{C}$ dengan seperlebar difraksi yang terbentuk dapat dilihat pada Gambar 3. Gambar 3 menunjukkan grafik hubungan antara suhu $(T)$ dan lebar difraksi (1/Z), yang menunjukkan bahwa nilai $1 / Z$ meningkat dengan bertambahnya T. Alhasil, hasilnya bisa dikatakan linier. Berdasarkan tinjauan data, nilai $a=2,911 \pm 0,904 \mathrm{C} / \mathrm{m}$, dan nilai $b=302,796 \pm 56,824 \mathrm{C} / \mathrm{m}$. Koefisien muai panjang aluminium dapat dihitung dengan menggunakan nilai $a=2,911 \pm 0,904 \mathrm{C} / \mathrm{m}, \lambda=(640,00 \pm 0,20) \times 10^{-9} \mathrm{~m}, D=1,43 \pm 0,05 \mathrm{~m}$ dan $L_{0}=0,09 \pm 0,05 \mathrm{~m}$ ke dalam persamaan (3).

Tabel 1. Data hasil percobaan Alumunium

\begin{tabular}{cccc}
\hline No. & $\boldsymbol{T}\left({ }^{\circ} \mathbf{C}\right)$ & $\boldsymbol{Z}(\mathbf{m})$ & $\mathbf{1 / Z}\left(\mathbf{m}^{-1}\right)$ \\
\hline 1. & 30 & 0,0025 & 400,0000000 \\
2. & 35 & 0,0024 & 416,6666667 \\
3. & 40 & 0,0024 & 416,6666667 \\
4. & 45 & 0,0024 & 416,6666667 \\
5. & 50 & 0,0022 & 454,5454545 \\
6. & 55 & 0,0022 & 454,5454545 \\
7. & 60 & 0,0022 & 454,5454545 \\
8. & 65 & 0,0020 & 500,0000000 \\
9. & 70 & 0,0020 & 500,0000000 \\
10. & 75 & 0,0019 & 526,3157895 \\
11. & 80 & 0,0018 & 555,5555556 \\
12. & 85 & 0,0018 & 555,5555556 \\
13. & 90 & 0,0018 & 555,5555556 \\
\hline
\end{tabular}




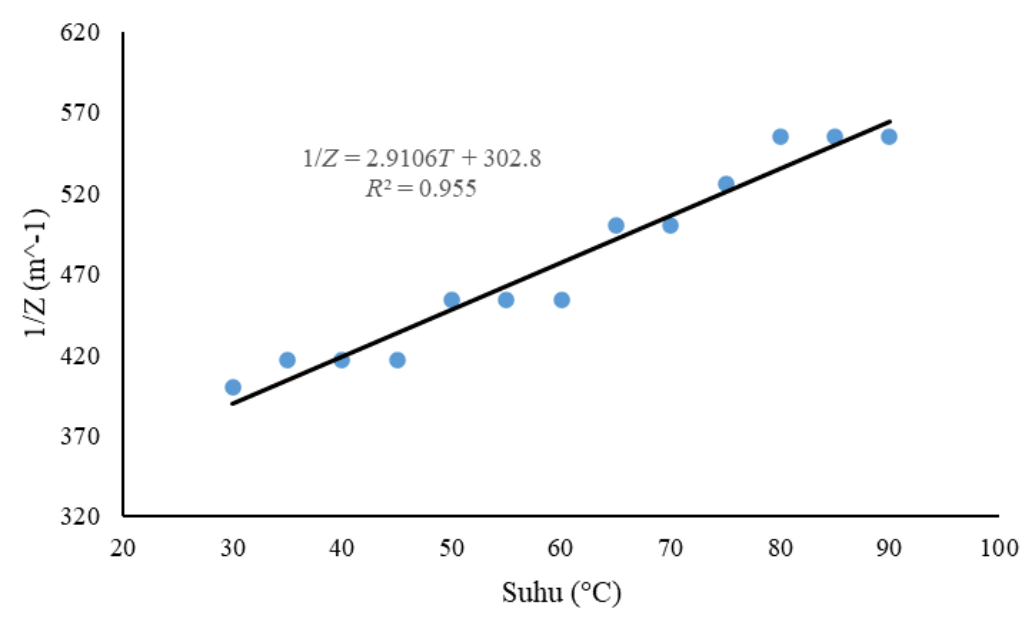

Gambar 3. Grafik hasil percobaan untuk logam Alumunium (Al)

Nilai koefisien pemuaian logam Alumunium yang diperoleh dari hasil analisis regresi linier dan nilai ralat dari persamaan (3) dan (4) berturut-turut diperoleh nilai $\alpha=(29,597549 \pm 0,000045) \times 10^{-6}\left({ }^{\circ} \mathrm{C}\right)^{-}$ ${ }^{1}$ dengan nilai acuan yaitu $24 \times 10^{-6}\left({ }^{\circ} \mathrm{C}\right)^{-1}$, sehingga ralat relatif diperoleh sebesar $23,32 \%$. Nilai ralat ini masih tergolong cukup besar.

Tabel 2 menunjukkan bahwa menaikkan suhu sebesar $5^{\circ} \mathrm{C}$ menghasilkan lebar difraksi yang berbeda untuk seng (Zn). Dengan naiknya suhu, nilai lebar difraksi berkurang. Lebar difraksi berbanding terbalik dengan kenaikan suhu. Logam Zn mengembang seiring naiknya suhu air panas, menghasilkan diameter difraksi yang lebih sempit.

Tabel 2. Data hasil percobaan Seng

\begin{tabular}{cccc}
\hline No. & $\boldsymbol{T}\left({ }^{\mathbf{0}} \mathbf{C}\right)$ & $\boldsymbol{Z}(\mathbf{m})$ & $\mathbf{1 / Z}\left(\mathbf{m}^{-1}\right)$ \\
\hline 1. & 30 & 0,0034 & 294,1176471 \\
2. & 35 & 0,0032 & 312,5000000 \\
3. & 40 & 0,0031 & 322,5806452 \\
4. & 45 & 0,0029 & 344,8275862 \\
5. & 50 & 0,0027 & 370,3703704 \\
6. & 55 & 0,0026 & 384,6153846 \\
7. & 60 & 0,0025 & 400,0000000 \\
8. & 65 & 0,0024 & 416,6666667 \\
9. & 70 & 0,0023 & 434,7826087 \\
10. & 75 & 0,0023 & 434,7826087 \\
11. & 80 & 0,0022 & 454,5454545 \\
12. & 85 & 0,0021 & 476,1904762 \\
13. & 90 & 0,0021 & 476,1904762 \\
\hline
\end{tabular}

Dari data yang diperoleh, maka grafik yang terbentuk antara perubahan suhu setiap kenaikan $5^{\circ} \mathrm{C}$ dengan seperlebar difraksi yang terbentuk dapat dilihat pada Gambar 4. Gambar 4 menunjukkan grafik hubungan antara suhu $(T)$ dan lebar difraksi $(1 / Z)$, yang menunjukkan bahwa nilai $1 / Z$ meningkat dengan bertambahnya T. Alhasil, hasilnya bisa dikatakan linier. Nilai $a=3,153 \pm 0,963 \mathrm{C} / \mathrm{m}$, dan nilai $b=204,816$ $\pm 60,544 \mathrm{C} / \mathrm{m}$. Memasukkan nilai $a=3,153 \pm 0,963 \mathrm{C} / \mathrm{m}, \lambda=(640,00 \pm 0,20) \times 10^{-9} \mathrm{~m}, D=1,43 \pm 0,05$ $m$ dan $L_{0}=0,09 \pm 0,05 m$ ke dalam persamaan (3) untuk mencari besarnya koefisien muai panjang seng. Nilai koefisien pemuaian logam Seng yang diperoleh dari hasil analisis regresi linier dan nilai ralat dari 
persamaan (3) dan (4) berturut-turut diperoleh nilai $\alpha=(32,065406 \pm 0,000096) \times 10^{-6}\left({ }^{\circ} \mathrm{C}\right)^{-1}$ dengan nilai acuan yaitu $29 \times 10^{-6}\left({ }^{\circ} \mathrm{C}\right)^{-1}$, sehingga ralat relatif diperoleh sebesar $10,57 \%$. Nilai ralat yang diperoleh ini masih cukup besar.

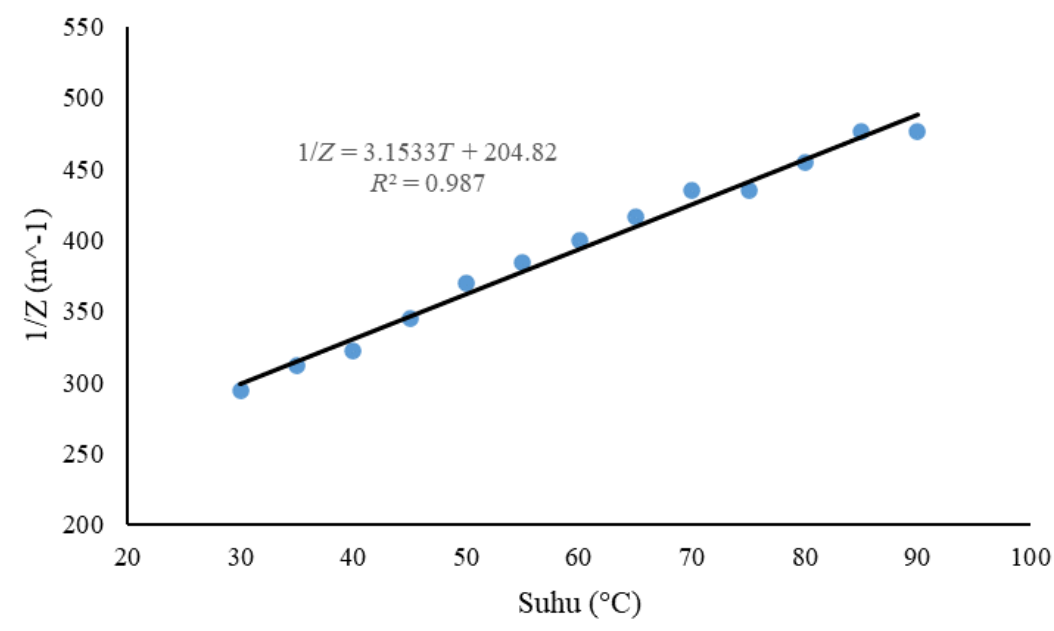

Gambar 4. Grafik hasil percobaan untuk logam Seng (Zn)

Setiap kenaikan $5^{\circ} \mathrm{C}$ pada tembaga (Cu) menghasilkan lebar difraksi yang berbeda, seperti terlihat pada Tabel 3. Dengan naiknya suhu, nilai lebar difraksi menurun. Logam tembaga (Cu) mengembang saat suhu air panas naik, menghasilkan diameter difraksi yang lebih sempit.

Tabel 3. Data hasil percobaan Tembaga

\begin{tabular}{cccc}
\hline No. & $\boldsymbol{T}\left({ }^{\mathbf{0}} \mathbf{C}\right.$ & $\boldsymbol{Z}(\mathbf{m})$ & $\mathbf{1 / Z}\left(\mathbf{m}^{-1}\right)$ \\
\hline 1. & 30 & 0,0098 & 102,0408163 \\
2. & 35 & 0,0095 & 105,2631579 \\
3. & 40 & 0,0090 & 111,1111111 \\
4. & 45 & 0,0085 & 117,6470588 \\
5. & 50 & 0,0080 & 125,0000000 \\
6. & 55 & 0,0078 & 128,2051282 \\
7. & 60 & 0,0072 & 138,8888889 \\
8. & 65 & 0,0070 & 142,8571429 \\
9. & 70 & 0,0068 & 147,0588235 \\
10. & 75 & 0,0067 & 149,2537313 \\
11. & 80 & 0,0065 & 153,8461538 \\
12. & 85 & 0,0061 & 163,9344262 \\
13. & 90 & 0,0058 & 172,4137931 \\
\hline
\end{tabular}

Dari data yang diperoleh, maka grafik yang terbentuk antara perubahan suhu setiap kenaikan $5^{\circ} \mathrm{C}$ dengan seperlebar difraksi yang terbentuk dapat dilihat pada Gambar 5. Gambar 5 menunjukkan grafik hubungan antara suhu $(T)$ dan lebar difraksi (1/Z), yang menunjukkan bahwa nilai $1 / Z$ meningkat dengan bertambahnya T. Alhasil, hasilnya bisa dikatakan linier. Berdasarkan analisis data, nilai $a=1,143 \pm 0,345$ $\mathrm{C} / \mathrm{m}$ dan $b=66,614 \pm 21,996 \mathrm{C} / \mathrm{m}$. Memasukkan nilai $a=1,143 \pm 0,345 \mathrm{C} / \mathrm{m}, \lambda=(640,00 \pm 0,20) \times 10^{-9}$ $\mathrm{m}, D=(1,43 \pm 0,05) \mathrm{m}$ dan $L_{0}=0,09 \pm 0,05 \mathrm{~m}$ ke dalam persamaan (3) untuk mencari besarnya koefisien ekspansi panjang Tembaga. Nilai koefisien pemuaian logam Tembaga yang diperoleh dari hasil analisis regresi linier dan nilai ralat dari persamaan (3) dan (4) berturut-turut diperoleh nilai $\alpha=$ 
$(11,622974 \pm 0,000013) \times 10^{-6}\left({ }^{\circ} \mathrm{C}\right)^{-1}$ dengan nilai acuan yaitu $17 \times 10^{-6}\left({ }^{\circ} \mathrm{C}\right)^{-1}$, sehingga ralat relatif diperoleh sebesar $31,63 \%$. Nilai ralat ini masih terlalu besar.

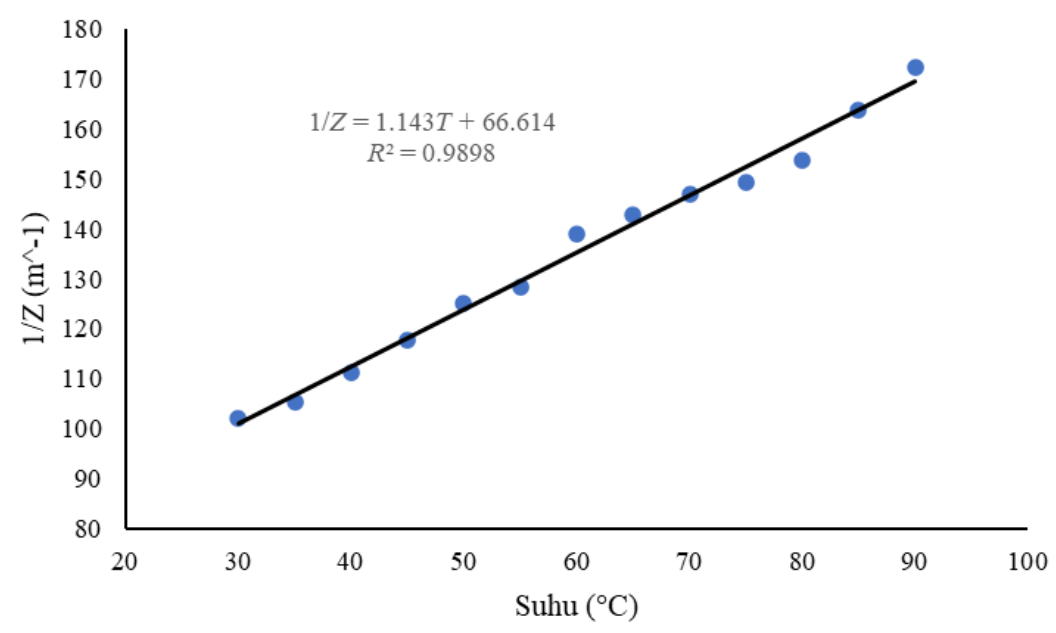

Gambar 5. Grafik hasil percobaan untuk logam Tembaga (Cu)

Pemuaian panjang dari tiga jenis logam yang berbeda dihitung berdasarkan analisis data menggunakan proses difraksi celah tunggal regresi linier. Setiap kenaikan suhu menghasilkan nilai seperlebar difraksi. Kenaikan suhu yang sangat cepat menjadi satu kendala. Jarak difraksi harus diukur dengan cepat. Menghitung konsentrasi dari pendeteksian variasi suhu pada termometer dan menghitung lebar difraksi yang dihasilkan sulit dilakukan jika dilakukan secara terpisah. Karena jarak layar $(D)$ adalah 1,43 m, maka hal ini terjadi. Karena diameter difraksi yang dihasilkan sangat pendek, diperlukan ketelitian tinggi untuk mendapatkan hasil yang akurat dalam satuan milimeter.

\section{Simpulan}

Dari hasil analisis dapat diketahui bahwa penentuan koefisien muai panjang logam dengan proses difraksi celah tunggal lebih akurat dalam menentukan koefisien muai logam aluminium (Al) pada khususnya dan logam lain pada umumnya, seperti seng ( $\mathrm{Zn}$ ) dan logam tembaga (Cu). Setiap kenaikan suhu yang terjadi akan memperbesar nilai seperlebar difraksi yang dihasilkan. Berdasarkan analisis data yang dilakukan dari ketiga logam yaitu Alumunium (Al), Seng (Zn) dan Tembaga (Cu) menggunakan regresi linier nilai koefisien muai panjang dari ketiga logam yaitu logam Alumunium sebesar $(29,597549 \pm 0,000045) \times 10^{-6}\left({ }^{\circ} \mathrm{C}\right)^{-1}$ dengan nilai acuan sebesar $24 \times 10^{-6}\left({ }^{\circ} \mathrm{C}\right)^{-1}$ sehingga diperoleh ralat relatif sebesar $23,32 \%$, Seng sebesar $(32,065406 \pm 0,000096) \times 10^{-6}\left({ }^{\circ} \mathrm{C}\right)^{-1}$ dengan nilai acuan sebesar $29 \times$ $10^{-6}\left({ }^{\circ} \mathrm{C}\right)^{-1}$ sehingga diperoleh ralat relatif sebesar $10,57 \%$ dan Tembaga sebesar $(11,622974 \pm 0,000013)$ $\times 10^{-6}\left({ }^{\circ} \mathrm{C}\right)^{-1}$ dengan nilai acuan sebesar $17 \times 10^{-6}\left({ }^{\circ} \mathrm{C}\right)^{-1}$ sehingga diperoleh ralat relatif sebesar $31,63 \%$. Besarnya ralat relatif tersebut menunjukkan bahwa alat ini tidak cukup akurat untuk menentukan koefisien muai panjang, namun demikian secara konsep benar. Sehingga direkomendasi dapat digunakan sebagai alat demonstrasi. 


\section{References}

Abdullah, M. (2016). Fisika dasar 1. Bandung: Institut Teknologi Bandung.

Bharmanee, P., Thamaphat, K., \& Limsuwan, P. (2008). Measurement of a thermal expansion coefficient for a metal by diffraction patterns from a narrow slit. Nat. Sci., 42, 346-350.

Evans, D., \& Morgan, J. T. (1991). Low temperature mechanical and thermal properties of liquid crystal polymers. Cryogenics, 31(4), 220-222.

Fakhruddin, H. (2006). Quantitative investigation of thermal expansion using single-slit diffraction. AAPT Physics Education, 44(2), 82.

Ferawati, R., \& Okimustava. (2012). Penentuan koefisien pemuaian panjang alumunium (Al) menggunakan metode difraksi celah tunggal. In M. Toifur, Widodo, \& Ishafit (Eds.), Kompetensi Lulusan Fisika \& Pendidikan Fisika Menghadapi Kebijakan KKNI (pp. 57-61). HMPS Pendidikan Fisika Universitas Ahmad Dahlan.

Jua, S. K., Sarwanto, \& Sukarmin. (2017). Pengembangan alat percobaan muai panjang zat padat sebagai alat praktikum fisika pada materi pemuaian. Prosiding Seminar Nasional Pendidikan Fisika III, 122-129.

Pujayanto, P., Budiharti, R., Radiyono, Y., Masithoh, D. F., \& Arfian, F. (2016). Pembuatan alat percobaan pengukuran koefisien pemuaian panjang logam dengan difraksi. Seminar Nasional Pendidikan Sains VI, 263-268.

Sariyanto, E., Suciyati, S. W., Pauzi, G. A., \& Junaidi. (2014). Pengukuran panjang gelombang sumber lampu monokromatis dari pola difraksi cahaya berbasis webcam dan borland delphi. Jurnal Teori dan Aplikasi Fisika, 02(02), 199-204.

Serway, R. A., \& Jewett, J. W. J. (2010). Fisika untuk Sains dan Teknik. Jakarta: Salemba Teknika.

Sugianto, A. I. (2007). Penentuan koefisien muai panjang logam besi dengan metode interferensi cincin newton. Yogyakarta: Universitas Sanata Dharma.

Usman, A. A., \& Rahmawati, E. (2016). Menentukan koefisien muai termal logam menggunakan sistem pengukuran digital. Jurnal Inovasi Fisika Indonesia (IFI), 5(3), 6-8.

Wolff, E. G., \& Eselun, S. A. (1979). Thermal expansion of a fused quartz tube in a dimensional stability test facility. Review of Scientific Instruments, 50(4), 502-506.

Wulandari, P., \& Radiyono, Y. (2015). Penggunaan metode difraksi celah tunggal pada penentuan koefisien pemuaian panjang alumunium (Al). Jurnal Materi dan Pembelajaran Fisika, 5(2), 19-22.

Yantidewi, M., Prastowo, T., \& Arief, A. (2018). Pengukuran koefisien muai volume minyak nabati dan air berdasarkan relasi linear antara perubahan volume dan perubahan temperatur. JIPFRI (Jurnal Inovasi Pendidikan Fisika dan Riset Ilmiah), 2(1), 43-48.

Yogaswara, Y., \& Latief, F. D. E. (2018). The development of experimental sets for measuring linear thermal expansion coefficient of metal using digital video-based single slit diffraction method. Jurnal Penelitian \& Pengembangan Pendidikan Fisika, 4(2), 141-152. 